\title{
Enhancing Teacher Autonomy Support within Flipped Classroom Teaching Mode
}

\author{
Huanhuan Ren ${ }^{1, a^{*}}$ and Chi Ma ${ }^{2, b}$ \\ ${ }^{1}$ Teaching and Research Institute of Foreign Languages, Bohai University, Jinzhou 121013, China \\ 2 Jinzhou Institute of Forestry Research, Jinzhou Forestry Bureau, Jinzhou 121013, China \\ arenhuanhuan2014@163.com, ${ }^{b}$ machi2014@tom.com
}

\section{Keywords: Teacher Autonomy Support; Flipped Classroom; Teaching Mode}

\begin{abstract}
Teacher autonomy support makes autonomous learning possible and efficient. It's argued that the issue of teacher autonomy support is crucial to flipped classroom efforts. In this article, we offer a way of thinking about autonomy-supportive practices that suggests that such practices will work for flipped classroom teaching mode. Specifically, we propose that autonomy support can be manifested under the flipped classroom teaching context in at least four distinct ways: supporting learners with various strategies, supporting learners with inner motivational resources, supporting learners with team opportunities, and supporting learners with critical mindset in autonomous learning, so as to maximize academic outcomes even while fostering learner autonomy and innovation.
\end{abstract}

\section{Introduction}

The development of learner autonomy is practically impossible without teacher autonomy support. As many have noted, teacher autonomy support makes autonomous learning possible and efficient. This study investigated the construct of teacher autonomy support in the context of flipped classroom, so as to maximize academic outcomes even while fostering learner autonomy and innovation. In the meanwhile, types of autonomy support are identified so that teachers know what to say and do to support students' learning achievement. This article is a summary of this research work, hopefully providing theoretical support and guidance for instructors who are going for a flipped classroom in future practice.

\section{Introduction of Learner Autonomy and Teacher Autonomy Support}

Benefits of Learner Autonomy. Learner autonomy is identified as a construct of complicated capacity for making informed decisions about one's own learning and taking control of one's own learning[1]. The purpose of autonomous learning is to encourage students to move from teacher-directed learning (in which knowledge of the language and skills are imparted by the teacher) to self-directed learning (in which the ability to learn independently are cultivated in addition to language knowledge and skills)[2]. All students need and benefit from learner autonomy. It's shown that perceived autonomy correlates with a host of positive outcomes, such as greater engagement, more positive emotionality, greater conceptual learning, preference for optimal challenge, greater school retention, higher academic achievement [3]. There is some truth in the idea that those who perceive that they have less autonomy are more likely to yield less satisfying and fruitless learning results. It's advisable to cultivate language learners' autonomous learning ability in line with their respective needs and situation, and at the same time teachers need to relinquish some of their control over learners by allowing students to experience responsibility for their learning[4].

Wisdom behind Teacher Autonomy Support. In light of learner autonomy, what kind of roles are teachers supposed to play in educational setting? Should teachers be autonomy supportive or autonomy controlling? Teachers motivate students using interpersonal styles that range from highly controlling to highly autonomy supportive[5]. Teacher autonomy support is viewed as interpersonal 
sentiment and behavior teachers provide during instruction to identify, nurture, and develop students' inner motivational resources[6]. According to Deci, autonomy support is a personal orientation that influences interaction[7]. In the interaction there are skills acquired by teacher to support the autonomy of others such as taking other person's perspectives, acknowledging feelings and making information available for decision making. The opposite of autonomy support is controlling. It's shown that an autonomy-supportive motivating style is more strongly associated with positive outcomes than controlling style[8]. Specifically speaking, an autonomy supportive teacher nurtures and increases students' inner endorsement in classroom activity[9]. It's also found that students show a strong, immediate, and positive engagement effect when teachers enact autonomy-supportive instructional behaviors [10].

\section{Needs for Teacher Autonomy Support within Flipped Classroom Teaching Mode}

Towards Flipped Classroom Teaching Mode. Recently going for a flipped classroom is becoming a true global fad in educational scenarios. The idea behind flipped classroom teaching approach is just flipping the whole thing around. To be exact, flipped classroom inverts traditional teaching methods through delivering instruction online outside of class and moving homework into the classroom[11]. It's grounded in many dominant learning theories. Constructive theory, humanistic education and learner autonomy constitute basic rationales for the adoption of flipped classroom teaching mode[12]. It's found that four main things in pedagogy may be transformed or inverted through flipping classroom, including the subversion of learning time and place, the subversion of instructional model, the subversion of responsibility and power, and the subversion of personal relationship[13]. All in all, flipping the classroom means completely re-thinking how to do the job people have done a certain way for years, and educators from around the world are experimenting with the idea of a flipped classroom model for promising results[14].

Implication of Teacher Autonomy Support. The issue of autonomy support is crucial to flipped classroom efforts because of the prevalence of underachievement within flipped classroom teaching mode. On the surface, flipped classroom is about shifting from passive learning to active learning[15]. The gist is, however, about the matter of power, ability and responsibility of learners in learning. It's demanded that learners should be good at learning autonomously, namely taking charge of their own learning technically, psychologically and politically. In this regard, teachers aren't quite wise in exerting a moderate or even great degree of control over their classrooms, as the tendency towards a controlling motivating style within flipped classroom is an unfortunate state of affairs. Rather, teachers ought to learn to be more autonomy-supportive toward their students so as to facilitate the developing sense of student autonomy. In a word, teacher autonomy support may be seen as antidote to low achievement, high levels of student's boredom and disaffection within existing flipped classroom teaching mode.

\section{Approaches of Enhancing Teacher Autonomy Support within Flipped Classroom Teaching Mode}

Supporting Learners with Various Strategies in Autonomous Learning. A few things may come easily to learners but most strategies in learning arrives after effort. Good teachers are willing to put in the time to help learners with them. A large body of meta-cognitive strategies should be integrated into autonomous learning, for example, planning, monitoring, and evaluating one's work. It requires teachers to assist learners in obtaining moment-to-moment feedback needed to tackle the problem at hand, so that learners tend to make sure how well their efforts to boost achievement in learning. As well, learners ought to become better at taking the lead on sophisticated cognitive strategies, such as elaborating, summarizing and rehearsing. Efforts and endeavors of teachers should be directed in this regard under flipped classroom teaching context. Most notably, supporting learners with learning strategies is a critical component of any strategic plan to boost the effectiveness of learner behaviors. 
Supporting Learners with Inner Motivational Resources in Autonomous Learning. There are obvious benefits of generating inner motivational resources of learners within flipped classroom mode. It's concurred that student's positive motivation in learning activities lead to big students' autonomy. However, autonomy is undermined by policies that reinforce management practices that are controlling. Therefore, learners should not rely on external regulators, such as assignments, compliance requests, etc. Learners with motivational problems are intended to be responded through various approaches. It's suggested that teachers build instructional activities around students so as to nurture their inner motivational resources, such as interests, enjoyment, sense of being challenged and preferences, psychological needs and internalized values, etc. Doors open as learners engage in learning with both behavioral involvement and emotional engagement whist teachers supporting learners with inner endorsement under flipped classroom teaching context.

Supporting Learners with Team Opportunities in Their Autonomous Learning. Understanding socio-cultural influences on student autonomy is essential. In other words, learners should be involved into a large learning setting (i.e. social learning) through commuting and cooperating with many other people, including peer students, teachers, etc. As autonomous learners are malleable, it makes sense to give serious considerations to team opportunities that aim to enhance students' achievement in learning through active interaction. In addition to classroom activities, teachers are supposed to provide instructional supports meant to foster team work outside of class. It's especially true to flipped classroom teaching mode since flipped classroom opens up additional time in class for more productive, interactive activities than traditional lectures teachers have been giving. The potential of learners will be evoked provided teachers' autonomy-supportive behaviors during second classroom observation are followed. The move is critical and essential to one who is set to be an efficient autonomous learner under flipped classroom teaching context.

Supporting Learners with Critical Mindset in Their Autonomous Learning. There is one aspect that cannot be ignored when one assist learners in establishing learner autonomy, and that is critical mindset. There are inevitable conflict between what teachers want students to do and what students want students to do. How to strike the balance is no more than a test pertinent to critical thinking. Learners are encouraged to think independently and innovatively other than obeying commands and directions from teachers. Through relinquishing control to learners and showing respect and understanding, ideas and values from learners should be accepted and considered as opposed to being opposed and criticized. An expression of the self during task involvement, such as offering suggestions, recommending activities, expressing interest and preferences, asking questions about what is being learned, should be welcomed all along. Over time, voices of learners are meant to be heard. It's advisable that teachers become more autonomy supportive through cultivating critical mindset of learners under flipped classroom context.

\section{Epilogue}

From above, teacher autonomy support within flipped classroom is essential for learners to sustain positive learning outcomes. We offer a way of thinking about autonomy-supportive practices that suggests that such practices will work for flipped classroom teaching mode. Specifically, we propose that autonomy support can be manifested under the flipped classroom teaching context in at least four distinct ways: supporting learners with various strategies, supporting learners with inner motivational resources, supporting learners with team opportunities, and supporting learners with critical mindset in autonomous learning, so as to maximize academic outcomes even while fostering autonomy and innovation in the learning process.

\section{Acknowledgements}

This work is part of the project of Research on Teacher Autonomy Support and Teacher Emotional Guide under College English Flipped Classroom Teaching Context, the project of On Cultivating and Developing Liaoning Scientific Foreign Language Talents with View to Bourdieu' Theory, the project 
of On Establishing Generative Mechanism of EFL Autonomous Learning Behaviors and Strengthening Development of Learning Field in Ubiquitous Learning Space, and the project of On Constructing Mechanism and Strategies for College English Autonomous Learning Abilities via Mobile Multimedia. This research was supported by the fund of Bohai University Teaching Reform Research (Project No. BDJG2016QC09), the fund of Liaoning Planning of Philosophy and Social Science (Project No. L16CYY001), the fund of Liaoning Provincial Federation Social Science Circles (Project No. 2017lslktyb-019), and the fund of the Thirteenth Five-Year Plan of Education Sciences of Liaoning Province (Project No. JG16DB013).

\section{References}

[1] H.-H. Ren, C. Ma. Designing practical training system for EFL learner autonomy in view of local economic development. In X. Liu and G. Xu (eds.). Advances in Social Science, Education and Humanities Research V87. Paris: Atlantis Press. November 12-13, 2016, pp.648-651.

[2][4] H.-H. Ren, C. Ma. Strategies on Fostering English Autonomous Learning Ability under the Influence of Mobile Multimedia. Advances in Engineering Research V97. Paris: Atlantis Press. July 2016, pp.616-620.

[3][10] J. Reeve. How Teachers Can Promote Students' Autonomy During Instruction: Lessons from a Decade of Research. Iowa Educational Research and Evaluation Association 2005 Annual Conference. December 9, 2005.

[5] J. Reeve. Autonomy support as an interpersonal motivating style: Is it teachable? Contemporary Educational Psychology, 23 (1998), 312-330.

[6] How to Distinguish Autonomy Support from Control: Management behaviors that will meet or thwart basic human psychological needs. Retrieved from http://www.teach-kids-attitude-1st.com/autonomy-support.html

[7] E. L. Deci, R. M. Ryan. Human autonomy: The basis for true self-esteem. In M. Kernis (Ed.), Efficacy, agency, and self-esteem (pp.31-49). New York: Plenum Press, 1995.

[8] R. M. Ryan, E. L. Deci. Self-determination theory and the facilitation of intrinsic motivation, social development, and well-being. American Psychologist, 55(2000), 68-78.

[9] J. Reeve. Teachers as facilitators: What autonomy-supportive teachers do and why their students benefit, Elementary School Journal 106(2006): 225-36.

[11] H.-H. Ren, C. Ma. On the Application of Flipped Classroom in Cultivating Liaoning Scientific Foreign Language Talents. In J. Wang, N. Xin and H. Y. Zhou (eds.). Advances in Computer Science Research v 59. Paris: Atlantis Press. December 2016, pp.1402-1406.

[12][13][14][15] H.-H. Ren, C. Ma. On Exploring Flipped Classroom Teaching Mode Based on the Development of Information Technology. In J. Wang, N. Xin and H. Y. Zhou (eds.). Advances in Computer Science Research v 59. Paris: Atlantis Press. December 2016, pp.1337-1341. 